\title{
Age-Related Decrease in the Schaffer Collateral-Evoked EPSP in Awake, Freely Behaving Rats
}

\author{
C.A. Barnes, ${ }^{\dagger}$ G. Rao and G. Orr \\ Arizona Research Laboratories, Division of Neural Systems, Memory and Aging and \\ The Department of Psychology, University of Arizona, Tucson, AZ 85274, USA
}

\begin{abstract}
SUMMARY
Synaptic response size in the CA1 region of the hippocampus in aged rats is reduced for a given stimulus intensity, compared with that elicited in young rats. Consistent with the in vitro findings of reduced Schaffer collateral-evoked CA1 EPSPs in old rats, the population currents evoked to iontophoretically applied AMPA are also smaller relative to the presynaptic fiber potential amplitude. On the other hand, the size of the presynaptic fiber potential and amplitude of unitary intra-cellularly recorded EPSP responses do not change across age in the CA1 region. These electrophysiological findings are consistent with the hypothesis that old rats have fewer functional synaptic contacts per Schaffer collateral axon than do young rats. The possibility that this age change arises as a result of a differential tissue recovery response to in vitro preparation was examined in the present study. CA1 presynaptic fiber potential and EPSP amplitudes evoked by the stimulation of Schaffer collateral afferents were studied in intact, freely behaving young and old rats. We confirmed in vivo the pattern of
\end{abstract}

\footnotetext{
Corresponding author:

Life Sciences North Building, Rm 384

University of Arizona

Tuscon, AZ 85749, USA

voice: +1-520-626-2616; fax: +1-520-626-2618

e-mail : carol@nsma.arizona.edu
}

electrophysiophysiological results previously reported in vitro and found significant correlations between the synaptic response amplitudes and the accuracy of spatial behavior in the Morris swim task. The data suggest that changes in functional connectivity of old rats may be a significant contributor to cognitive changes during aging.

\section{KEYWORDS}

aging, hippocampus, CA1, synaptic loss, synaptic plasticity

\section{INTRODUCTION}

Excitatory transmission is mediated by AMPA and NMDA receptors in the hippocampus and elsewhere in central nervous system (for example Michaelis [1998] for review). The age-related decline in the fast, AMPA-mediated component of synaptic transmission at the CA3-CA1 Schaffer collateral pyramidal cell synapse in vitro has been well documented (Barnes et al. 1992, 1996, 1997; Bauman et al. 1992; Deupree et al. 1993; Foster \& Norris, 1997; Gribkoff \& Bauman, 1992; Jouvenceau et al. 1998; Landfield et al. 1986; Norris et al. 1998; Ouanounou et al. 1998, 1999; Papatheodoropoulos \& Kostopoulos, 1996; however see Shankar et al., 1998). This attenuation of the AMPA-mediated 
EPSP is consistent with observations of decreased AMPA binding in the aged rodent hippocampus (Clark et al., 1992; Magnussen, 1998; Magnussen \& Cotman, 1993; Nicolle et al., 1996; Wardas et al., 1997); other investigators have reported no change (Miyoshi et al., 1991) or increases in AMPA binding in aged, cognitively impaired rats relative to young rats (LeJeune et al., 1996). Other changes with age reported in AMPA receptor function include altered expression of hippocampal glutamate receptor subunits (Pagliusi et al., 1994) and a selective hippocampal-evoked response in old but not young hippocampal-evoked responses to the application of a protein phosphatase inhibitor (Norris et al., 1998). The latter data suggest a shift in the balance of protein kinase and protein phosphatase activity with aging. Outside the hippocampus, Jasek and Griffith (1998) observed an increased AMPA current density and a decreased receptor affinity with age in whole-cell path clamp from acutely dissociated medial septum and nucleus of the diagonal band neurons.

Age-related impairment in $\mathrm{AMPA}_{\mathrm{R}}$-mediated synaptic transmission at the Schaffer collateral-CA1 synapse has previously been examined only in vitro. The hippocampus slice preparation is routinely used to study the cellular mechanism of synaptic transmission (Dingledine, 1984; Kerkut \& Wheal, 1981; Schurr et al., 1984, 1989; Teyler, 1980; Reid et al., 1988); however, during slice preparation on electrophysiological processes in vitro, there may be age-dependent deleterious effects of the brief ischemic, anoxic period (for example Brierly \& Graham, 1984; Ordy et al., 1988; Kadar et al., 1998; Kirino, 1982; Pulsinelli et al., 1982; Gao et al., 1999). In fact, CA1 pyramidal cells are preferentially affected by such insults (Schandler et al., 1988), resulting in both electrophysiological (Xu \& Pulsinelli, 1996) and biochemical (Tanaka et al., 1997) changes in young animals. Because hippocampal tissue from aged rats may be especially vulnerable to anoxia (for example Roberts et al., 1990, 1995, 1998; Syková et al., 1998), it is important to verify that the same pattern of electrophysiological results are observed in vivo. Old rats also show larger changes in evoked hippocampal response sizes between waking and pentobarbital-anesthetized states (Barnes, 1979). Thus, an in vivo preparation that is free from anesthetics would be optimal for an age comparison. Stable chronic recordings in the CAl region, however, have been difficult to obtain using fixed electrode implants (Linseman \& Corrigall, 1981). For the present experiment we developed a moveable microdrive that could carry both recording and stimulating electrodes. With this method we were able to adjust the electrodes to optimize the recording fiber potential and EPSP responses in the awake state. Some of the data have been reported elsewhere in abstract form (Rao et al., 1996).

\section{METHODS}

\section{Experimental Subjects}

Behavioral testing was conducted on adult ( $n=17,9$ to 11 months) and old ( $n=19,26$ to 28 months) male retired breeder F344 rats from the colony maintained by the National Institute on Aging at Charles River Laboratories. Two old rats were eliminated from the experiment because they did not improve over trials in the visual version of the swim task. Electrophysiological data were subsequently collected from 17 rats in each group. The rats were single-housed in Plexiglass guineapig tubs, with free access to food, and maintained on a $12 / 12 \mathrm{~h}$ light-dark cycle. All behavioral and electrophysiological testing was performed during the dark phase of the light cycle.

\section{Behavioral Testing}

All animals were handled upon arrival and were given health checks for 1 to 3 wk before behavioral testing. The rats were tested in the 
Morris swim task to assess their spatial and visual discrimination ability before the electrode implantation. The behavioral apparatus consisted of a circular tank (183 cm diameter, $48 \mathrm{~cm}$ depth) in a $2.3 \times 2.7 \times 2.5$-meter room containing distal (pictures, bookcase, light sources) and proximal (metal panel, folding chair) cues. An escape platform $(11.5 \mathrm{~cm}$ in diameter) was in a fixed location in the northwest quadrant of the tank for the spatial version of the task and was randomly located in one of the four quadrants for the visual discrimination portion of the task, During the spatial trials, the platform was hidden from view by partially filling the tank with water $\left(26^{\circ} \mathrm{C}\right.$ to $29^{\circ} \mathrm{C}$ ) containing white, non-toxic Crayola paint to a level $1 \mathrm{~cm}$ above the escape platform surface. For the visual task, the platform extended $2 \mathrm{~cm}$ above the water level, and black duct tape was wrapped around the platform's periphery to enhance visibility. In addition, a cardboard cue was hung directly overhead. Each rat wore a black duct-tape jacket to enable position tracking by an overhead video camera, connected to a VP114 tracking unit (VHS Image, England). Custom software (TR, J. Forster; WMAZE, M. Williams) was used to generate and analyze a series of $x-y$ coordinates representing the rat's path).

On the first day of testing, each rat was placed into the water, 2 to 3 in from the platform, and then guided gently until its forepaws touched the platform. After climbing onto the platform, the rat was allowed to remain there for $60 \mathrm{sec}$ before its first spatial trial. The spatial component of the task consisted of each rat being given 3 blocks of 2 training trials per day for $4 \mathrm{~d}$ (24 trials total). During the inter-block intervals, the rats were placed in a heat-controlled incubator to maintain body temperature. At the start of each trial, the rat was released into the water, facing the tank wall, from one of seven peripherally located points. When the rat had located the escape platform or had swum for $60 \mathrm{sec}$, it was allowed to sit on the platform for $30 \mathrm{sec}$. Following the last spatial trial on day 4 , the hidden platform was removed for a single probe trial, in which the rat was allowed to swim for $60 \mathrm{sec}$. Following a 2-h rest period in the incubator, each rat was given 6 trials on the visible cue discrimination task. From trial to trial, both the platform location and the release location were randomized. Six more visible trials were given the following day, for a total of 12 trials.

Performance on the water task was assessed by the corrected integrated path length (CIPL) measure, the sum of the distances from the target at each acquired point during the trial with a correction factor to compensate for the initial distance from the goal for each starting location (Gallagher et al., 1993). For the probe trial, the number of target crossings (TC; crossings over the area that had been previously occupied by the escape platform), the average distance (AD) from the target, and the time spent searching in each quadrant were calculated. The animals showing impairment on the visible task (two old rats) were excluded from the electrophysiological part of the experiment.

\section{Electrophysiology}

Within 1 mo of behavioral testing, all animals underwent bilateral implantation of microdrives under sodium pentobarbital anesthesia $(40 \mathrm{mg} / \mathrm{kg}$ for the adult animals, $33 \mathrm{mg} / \mathrm{kg}$ for the old rats). The microdrives consisted of a pair of $60 \mu \mathrm{m}$ o.d. nichrome wire electrodes, mounted in an amphenol strip threaded with two stainless-steel rods (Figs. 1A, 1B). The electrodes were mounted parallel to one another on the amphenol strip, with a separation of approximately $300 \mu \mathrm{m}$, such that the tips were at the same position in the depth axis. About $100 \mu \mathrm{m}$ of insulation was stripped from the tip of the stimulating electrode. The recording electrode was implanted at $4.0 \mathrm{~mm}$ posterior to bregma, $2.8 \mathrm{~mm}$ lateral to the midline (Paxinos \& Watson, 1986), with the stimulating electrode 
positioned anterior and lateral to the recording electrode (approximately $30^{\circ}$ away from the sagittal plane). At the time of surgery, the electrode pair was advanced approximately $1 \mathrm{~mm}$ to $1.7 \mathrm{~mm}$ below the brain surface.

Each rat was allowed $1 \mathrm{wk}$ of postoperative recovery. The electrodes were then slowly advanced over a period of 4 to 6 days into CA1 stratum pyramidale, which was determined by the appearance of multiple unit activity. The depth at which the unit activity was maximal was noted, and the electrodes were subsequently advanced approximately $120 \mu \mathrm{m}$ into stratum radiatum until the evoked response was maximal. Stimulus pulses (biphasic $80 \mu \mathrm{sec}$ ) were delivered through the stimulating electrode while recording evoked responses (Fig. 1C) was amplified 100 times, filtered between $3 \mathrm{~Hz}$ and $3 \mathrm{Khz}$ (half-amplitude attenuation), and then recorded for offline analysis, using an 80386 computer and Workbench software (DataWave Corp., Broomfield,
Colorado, USA).

As the rat sat quietly in its home cage, averages of the Schaffer collateral evoked responses were recorded, at the following stimulus intensities: $0,25,50,75,100,125,150,175,200$, 250, 300, 350, 400, and $450 \mu \mathrm{A}$ (see Results section, Fig. 3A). The input/output curve measurement was repeated over the next several days. Averages of the components of the response at each intensity were then calculated for each rat.

The amplitudes of the presynaptic fiber potential (considered to be proportional to the number of fibers activate; Lomo [1971]) and the Schaffer collateral EPSP were measured by setting cursors at $.30 \mathrm{msec}$ and $.38 \mathrm{msec}$ and at $1.0 \mathrm{msec}$ and $2.0 \mathrm{msec}$, respectively, after stimulus onset and then taking the voltage difference between each pair of cursors. After all data acquisition had been completed, a small electrolytic lesion was made at the tip of the recording electrode by passing $10 \mu \mathrm{A}$ constant current for $7 \mathrm{sec}$ to aid in
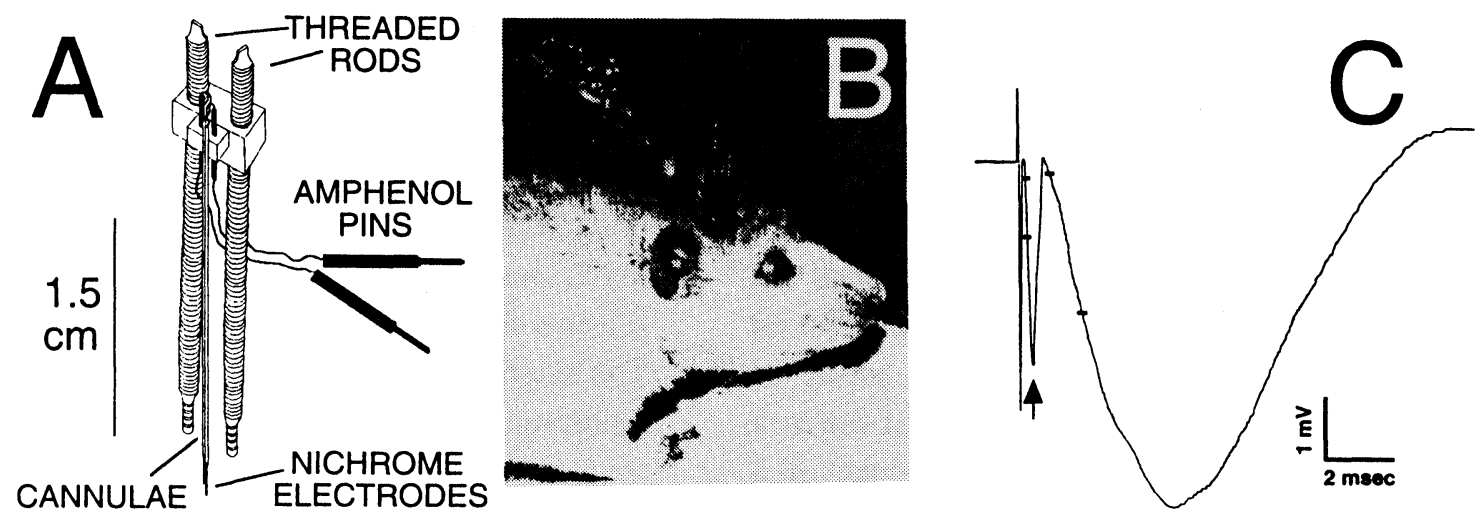

Fig. 1: A. Schematic of the implanted microdrive. A pair of 30 gauge cannulae, each containing a nichrome stimulating or recording electrode, is glued to an amphenol strip. The amphenol strip is loaded with two threaded stainlesssteel support rods whose legs have been filed down to remove the threads. Grooves are then cut in the legs, allowing the influx of dental acrylic that prevents the legs from moving vertically after the drive is implanted. B. Photograph of a rat with the microdrive apparatus. The animal is shown connected to preamplifying headstage and recording and stimulating cable. C. Example of the Schaffer collateral evoked response, consisting of the presynaptic fiber potential $(\boldsymbol{\uparrow})$ and the extracellular field EPSP. The cursors indicate the positions at which the fiber potential and the EPSP amplitudes were measured. 

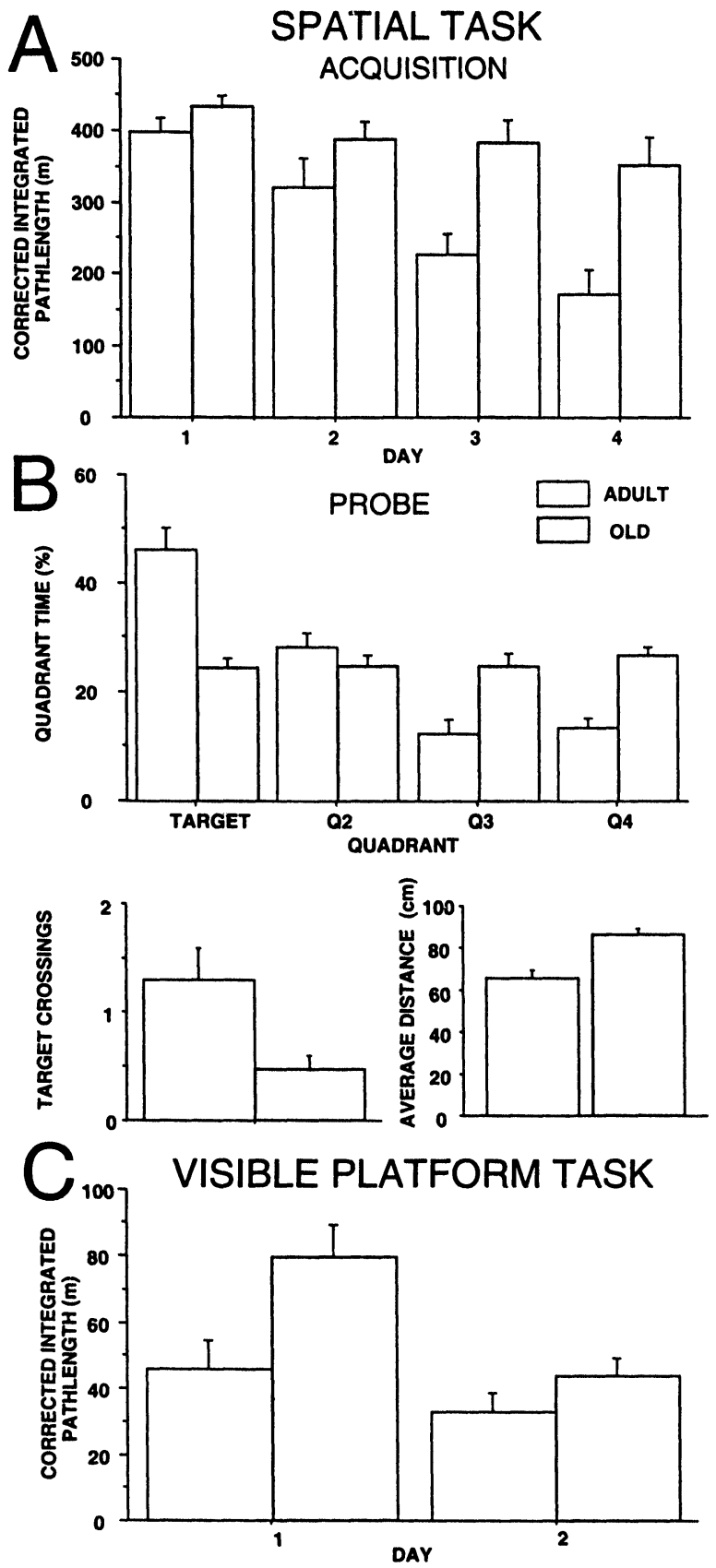

Fig. 2: A. Acquisition of the spatial version of the Morris swim task. The average of the CIPL for the six trials each day; the mean and the SE of the mean for each day is plotted for adult (open bar) and old (solid bar) rats. $\mathrm{B}$. The probe trial: number of target crossings, the average distance from the target, and time spent searching in each quadrant. C. Visible platform cuediscrimination task: no significant age difference was found on the second day. localizing the recording sites. The rats were perfused intracardially with a $4 \%$ formal-saline solution. Brain sections were prepared with a freezing microtome. Sections were places on a projection microscope to draw the lesion site and electrode tracks.

\section{RESULTS}

The visual acuity of two old animals could not be determined as these rats persisted in thigmotaxic behavior during the visible platform task. These rats were not included in the behavioral or electrophysiological data analyses.

\section{Behavior}

Spatial task. The corrected integrated path length (CIPL) was measured for the 24 spatial trials.

Acquisition. Acquisition of the spatial version of Morris swim task is presented in Fig. 2A. The means were calculated for each 6-trial block, equivalent to a day of training. The adult rats showed significant improvement in performance on the task over the 4 days. The old rats, although significantly better on the fourth day when compared with the first day, did not show an overall effect of day, indicating impaired learning of the task. A significant overall effect of age on CIPL was found for the spatial acquisition task $[F(1,32=22.764, p<0.0001)]$. No significant age effect on CIPL was found on the first 2 days of the spatial task [Day 1: $\mathrm{F}(1,32)=2.463, \mathrm{p}<0.1264$; Day 2: $\mathrm{F}(1,32)=2.21, \mathrm{p}<0.1469]$; the old animals performed significantly worse than did the young animals on the last two days [Day 3: $F(1,32)=$ 3.688, $p<0.0008$; Day 4: $F(1,32)=13.014, p<0.001]$, and did not show an overall significant effect of training day on performance $[F(3,16)=2.56$, $\mathrm{p}<0.0657]$. By contrast, the young rats showed 
improved performance over the 4 days $[\mathrm{F}(3,16)=$ 22.13, $\mathrm{p}<0.0001]$.

Probe: The escape platform was removed for a single probe following the last spatial acquisition trial (see Methods). For the probe trial (Fig. 2B), the time spent searching in each quadrant was measured for the 60-sec trial (Fig. 2B, upper graph). A significant overall effect of quadrant on the search time was found in young rats $[F(3,16)=31.487, p<0.0001]$, but not in old rats $[F(3,16)=0.265, p<0.8507]$. Young rats spent significantly more time in the target quadrant than in any other quadrant [Critical Difference= 7.955; Q2 vs target: Mean Diff. $=17.765, \mathrm{p}<0.0001$; Q3 vs target: Mean Diff. $=33.800, \mathrm{p}<0.0001$; Q4 vs target: Mean Diff. $=32.559, \mathrm{p}<0.0001]$. Old rats showed no preference for the target quadrant [Critical Diff. $=5.751$; Q2 vs target: Mean Diff. $=-0.306$, $\mathrm{p}<0.9157$; Q3 vs target: Mean Diff. $=-0.394$, $\mathrm{p}<0.8915$; Q4 vs target: Mean Diff. $=-2.300$, $\mathrm{p}<0.4273$ ]. Young rats were more accurate than were old rats in their search for the target location during the probe trial, as indicated by a significant effect of age on target crossings $[\mathrm{F}(1,32=6.644, \mathrm{p}<0.015)$; mean, adult $=1.294 \pm 0.294$; old $=0.882 \pm 0.173]$ and on the average distance from the target location $[\mathrm{F}(1,32=18.684, \mathrm{p}<0.0001)$; adult $=65.671 \pm 3.749$; old $=86.388 \pm 2.986]$. Adult rats preferentially searched in the quadrant that had preciously contained the escape platform. The search pattern for the old animals revealed no bias toward the target quadrant, verifying that the learning of the platform location was poorer than that in the young animals. The number of target crossings, traversals of the region that had been previously occupied by the target platform, was reduced in the old relative to the young group (lower left graph), indicating a less accurate search for the platform by the old animals. The mean distance to the target location throughout the 60-sec trial (average distance), for the old animals was significantly greater than that for the young (lower right graph).

Visible platform. The mean CIPL data show that the old animals were initially poorer than the young rats on this version of the task (Fig. 2C). A significant effect of age on CIPL in the visible task was present on the first day $[\mathrm{F}(1,32=7.038$, $\mathrm{p}<0.0123$ ], with old animals taking a longer path to the visible platform than that of the young rats (yg: mean CIPL $=46.02 \pm 8.07 \mathrm{~m}$; old: $79.78 \pm 9.38 \mathrm{~m}$ ). On the second day, however, no significant interaction between age and performance $[\mathrm{F}(1,32=1.880$, p<0.1798; yg: mean CIPL $32.78 \pm 5.84$ m; old: 43.88 $\pm 5.60 \mathrm{~m}]$ was observed. In contrast to the spatial version of the task, old animals showed a significant effect of training day on performance, indicating that they had learned the visible task [CIPL:F(1.16) $=10.797, p=0.0025]$.

\section{Electrophysiology}

Stimulus input/response output data were obtained for the Schaffer collateral-CA1 pyramidal cell responses were collected 2 to $3 \mathrm{wk}$ after surgery (Fig. 3A) and subsequently determined by histology to originate in stratum radiatum (Fig. 3B). A repeated measures ANOVA showed no significant effect of age on the pre synaptic fiber potential amplitude over the 14 stimulus intensities used (Fig. $4 \mathrm{~A} ;[\mathrm{F}(1,13)=0.136, \mathrm{p}=0.7152$; fiber potential amplitude at $150 \mu \mathrm{A}$ : adult $=0.349 \pm .029 \mathrm{mV}$; old $=0.386 \pm .033 \mathrm{mV}]$ ), confirming previous results (Barnes et al., 1992; Kerr et al., 1991). Also consistent with the data obtained in vitro, old rats showed reduced synaptic transmission at the Schaffer collateral-pyramidal cell synapse (Barnes et al., 1992, 1996, 1997; Bauman et al., 1992; Deupree et al., 1993; Gribkoff \& Bauman, 1992; Jouvenceau et al., 1998; Landfield et al., 1986; Papatheodoropoulos \& Kostopoulos, 1996). A repeated measures ANOVA, including all intensities of stimulation used, showed a significant effect of age on CA1 EPSP size relative to the fiber potential amplitude (Fig. 4B; $[\mathrm{F}(1,13)=6.302, \mathrm{p}=0.0124$; ratio of $\mathrm{EPSP} /$ fiber potential amplitude at $150 \mu \mathrm{A}$ : adult $=$ $3.013 \pm .339$; old $=1.929 \pm .187])$. The significantly 

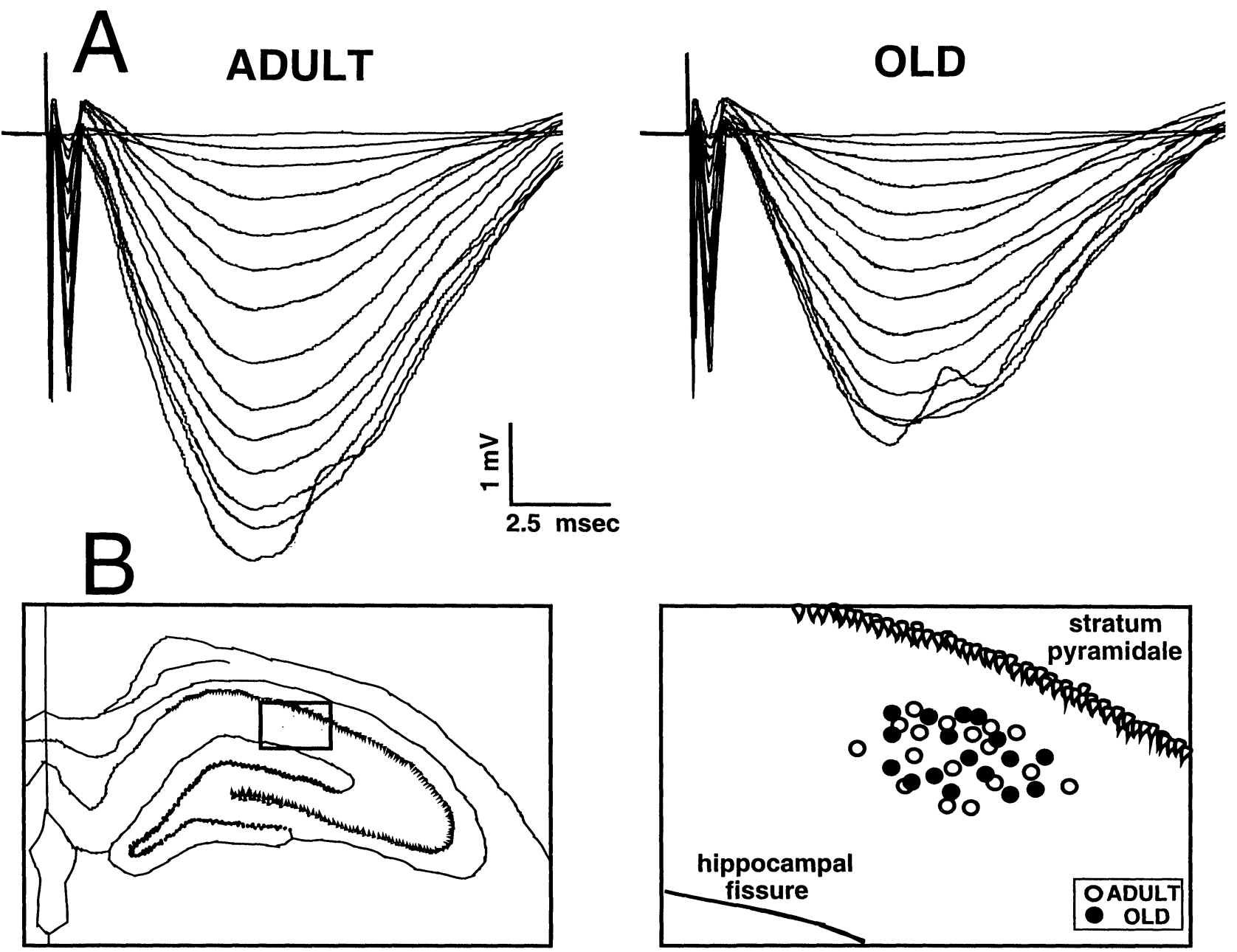

Fig. 3: A. Example of Schaffer collateral-CA1 pyramidal cell responses in one young and one old rat, collected at 14 different stimulus intensities. Each trace is an average of five individual evoked responses. B. Schematic diagram indicating the approximate locations of the recording sites at which the input-output series was conducted in CAl stratum radiatum $(\mathrm{O}$, adult; $\bullet$ old $)$.

smaller EPSP in old rats for a given fiber potential size provides in vivo confirmation of impaired glutamatergic transmission during aging. The mean latencies from stimulus onset to one/third of the maximal EPSP value were not significantly different between adult and old animals $[\mathrm{F}(1,32=0.051$, $\mathrm{p}<0.8229$; mean latency adult, $1.462 \pm .029$; old $1.470 \pm .030]$, indicating that the rise time of the extracellular EPSP was not affected by aging.

\section{Correlation between Behavior and Electrophysiology}

The relation between behavioral performance and the magnitude of the synaptic responses was assessed using the responses elicited at the 150, 300 , and $450 \mu \mathrm{A}$ stimulus levels. We chose these stimulus amplitudes because they spanned a large intensity range and represented equal increments. 

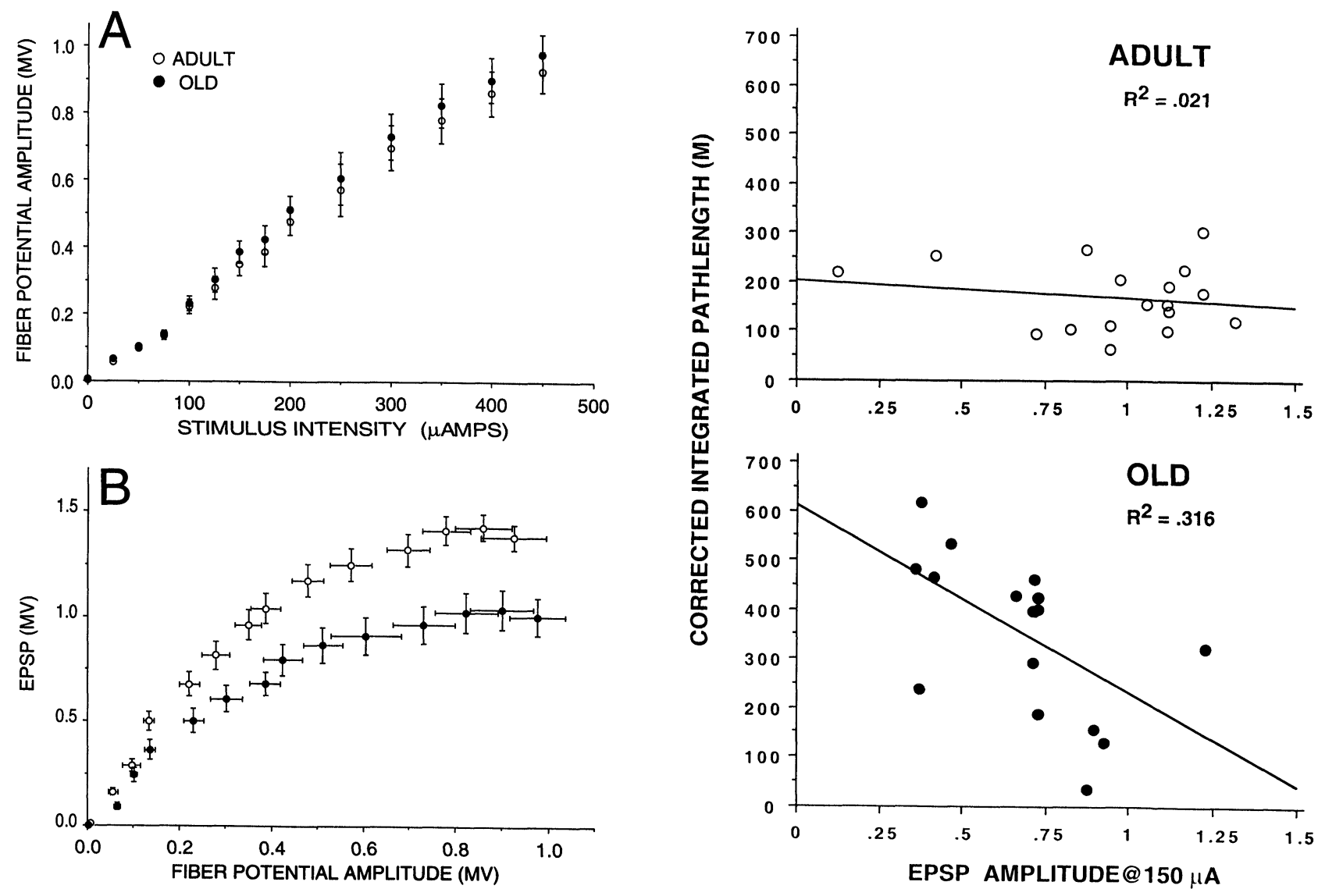

Fig. 4: Mean $( \pm S E)$ of the mean Schaffer collateral fiber potential amplitude, plotted for 14 stimulus levels $(O$, adult; $n=17 ; 0$ old, $n=17)$. B. Mean $( \pm S E)$ of the mean Schaffer collateralCA1 evoked EPSP plotted relative to the mean fiber potential amplitude.

Fig. 5: CIPL length during the probe trial of the spatial version of the Morris swim task plotted relative to the EPSP amplitude (elicited at the $150 \mu \mathrm{A}$ stimulus intensity). Young rats $(O)$ :no significant regression of behavior and EPSP amplitude; old rats (๑): significant regression between accuracy of spatial performance and the Schaffer collateralCA1 synaptic response amplitude (a reflection of functional synaptic contacts).

A significant correlation between the CIPL measure on the last day of the spatial task and the EPSP amplitude at the 150,300 , and $450 \mu \mathrm{A}$ stimulus levels was observed in the old rats (Fig. $5 ;[\mathrm{F}(1,16=$ $6.939, \quad \mathrm{p}<0.19 ; \mathrm{F}(1,16=5.704, \mathrm{p}<0.305, \quad$ and $\mathrm{F}(1,16=4.585, \mathrm{p}<0.491]$, respectively), but not in the younger animals $[\mathrm{F}(1,16=0.328, \mathrm{p}=0.575 ; \mathrm{F}(1,16=$ $0.331, \mathrm{p}=0.5738$, and $\mathrm{F}(1,16=0.331, \mathrm{p}<0.5738$, respectively). The average distance for the target during the probe was also significantly correlated with the EPSP size at the 150 , and $300 \mu \mathrm{A}$ levels in the old, but not young groups [old: $\mathrm{F}(1,16=4.585$, $\mathrm{p}<0.049$ and $\mathrm{F}(1,16=4.555, \mathrm{p}=0.0497$, respectively; adult $\mathrm{F}(1,16=0.0043, \mathrm{p}=0.9484 ;$ and $\mathrm{F}(1,16=$ $0.0057, p=0.944$, respectively]. Neither group reached statistical significance at the $450 \mu \mathrm{A}$ stimulus level for this measure [old: $\mathrm{F}(1,16=2.926$, $p<0.1078$; young $F(1,16=0.0043 p=0.948]$. 


\section{DISCUSSION}

The present results confirm in vivo the pattern of age-related changes in CA1 synaptic transmission that was previously fount in vitro. The amplitude of the Schaffer collateral-evoked presynaptic fiber potential did not differ between age groups, while the CA1 pyramidal cell synaptic response was smaller in the old rats. Thus, the age effects observed in vitro cannot be attributed to the differential recovery or stability of young and old brain tissue following slice preparation. Such a demonstration is important because clearly, changes in morphology and physiology do occur following slice preparation. For example, spine and synapse number in hippocampal slices are increased relative to perfusion-fixed hippocampus in vivo (Kirov et al., 1999); it was possible that age could have affected this process, leading to a spurious conclusion regarding the effects of age on synaptic transmission in the intact brain. In general, replication in vivo of such prominent effect as age on hippocampal neurophysiology provides a foundation for the interpretation of other studies on the effects of the aging process, which are currently technically possible only in the in vitro preparation (for example, Barnes \& McNaughton, 1980; Baskys et al., 1987; Billard et al., 1997; Campbell et al., 1996; Jouvenceau et al., 1998; Magnusson, 1998; Norris et al 197; Ouanounou et al. 1999; Potier et al., 1992; Reynolds \& Carlen, 1989; Rosenzweig et al., 1997; Shankar et al., 1998, Shen \& Barnes, 1996; Thibault \& Landfield, 1996).

The confirmation in vivo that old rats show smaller synaptic responses for a given pre synaptic fiber potential size is consistent with the hypothesis that old rats have fewer functional synaptic contacts on a given Schaffer collateral axonal branch. The two studies that have examined this question anatomically have failed to detect a difference between age groups on synapse numbers in the CA1 region (Scheff et al., 1985; Sullivan et al., 1997). This result suggests the possibility that anatomical synaptic contacts remain, but that some proportion of such synapses are not electrophysiologically functional in the old rats. On the other hand, because the rats in the synapse count studies were not behaviorally tested, the possibility cannot be excluded that the old rats in those experiments were not memory impaired. Therefore, the possibility remains that memoryimpaired old rats do lose anatomical contacts. Regardless of whether there are fewer actual or fewer functional contacts, the significant correlation in the present study between spatial accuracy in the Morris swim task and the amplitude of the synaptic response (a measure of the level of functional contacts) in old rats suggests a critical role of hippocampal synaptic connectivity in spatial cognition.

\section{ACKNOWLEDGEMENT}

We thank B.L. McNaughton for assistance in the development of the microdrive stimulating and recording apparatus used in these studies, and G.D. Stevenson and F.P. Houston for surgical assistance. This work was supported by AG03376, MH01227, and MH01565.

\section{REFERENCES}

Barnes CA. Memory deficits associated with senescence: a neurophysiological and behavioral study in the rat. J Comp Psychol 1979; 931: 74-104.

Barnes CA, McNaughton BL. Physiological compensation for loss of afferent synaptic in rat hippocampal granule cells during senescence. J Physiol (London) 1980; 309: 473-485.

Barnes CA, Rao G, Foster TC, McNaughton BL. Region-specific effects on AMPA sensitivity: electrophysiological evidence for loss of synaptic contacts in hippocampal field CA1. Hippocampus 1992, 2: 457-468.

Barnes CA, Rao G, McNaughton BL. Functional integrity of NMDA-dependent LTP induction 
mechanisms across the lifespan of F-344 rats. Learning and Memory 1996; 3: 124-137.

Barnes CA, Rao G, Shen J. Age-related decrease in the $n$-methyl-d-aspartate ${ }_{\mathrm{R}}$-mediated excitatory postsynaptic potential in hippocampal region CA1. Neurobiol Aging 1997; 18: 445-452.

Baskys A, Niesen CE, Carlen PL. Altered modulatory actions of serotonin on dentate granule cells of aged rats. Brain Res 1987; 419: 112-118.

Bauman LA, Mahle CD, Boissard CG, Gribkoff VK. Age dependence of effects of $\mathrm{A} 1$ adenosine receptor antagonism in rat hippocampus slices. J Neurophysiol 1992; 68: 629-638.

Billard JM, Jouvenceau A, Lamour Y, Dutar P. NMDA receptor activation in the aged rat: electrophysiological investigations in the $\mathrm{CA} 1$ area of the hippocampal slice ex vivo. Neurobiol Aging 1997; 18: 535-542.

Brierly JB, Graham DI. Hypoxia and vascular disorders of the central nervous system. In: Adams JH, Corselli JAN, Duchen LW, eds, Greenfield's Neuropathology. London, England: Edward Arnold 1984; 125-207.

Campbell LW, Hao SY, Thibault O, Blalock EM, Landfield PW. Aging changes in voltage-gated calcium currents in hippocampal CA1 neurons. J Neurophysiol 1996; 16: 6286-6295.

Clark AS, Magnussen KR, Cotman, CW. In vitro autoradiography of hippocampus excitatory amino acid binding in aged Fischer 344 rats: relationship to performance on the Morris water maze. Behavioral Neurosci 1992; 106: 324-335.

Deupree DL, Bradley J, Turner DA. Age-related alterations in potentiation in CA1 region in F344 rats. Neurobiol Aging 1993; 14: 249-258.

Dingledine R. Brain Slices. New York, NY, USA: Plenum Press, 1984.

Foster TC, Norris CM. Age-associated changes in $\mathrm{Ca}^{2+}$-dependent processes: relation to hippocampal synaptic plasticity. Hippocampus 1997; 7: 602-612.

Gallagher M, Burwell R, Burchinal M. Severity of spatial learning impairment in aging: development of a learning index for performance in the Morris water maze. Behav Neurosci 1993; 107: 618-626.

Gao TM, Pulsinelli WA, Xu ZC. Changes in membrane properties of $\mathrm{CA} 1$ pyramidal neurons after transient forebrain ischemia in vivo. Neuroscience 1999; 90: 771-780.

Gribkoff VK, Bauman LA. Endogenous adenosine contributes to hypoxic synaptic depression in hippocampus from young and old aged rats. $\mathrm{J}$
Neurophysiol 1992; 68: 620-628.

Jasek MC, Griffith WH. Pharmacological characterization of ionotropic excitatory amino acid receptors in young and aged rat basal forebrain. Neuroscience 1998; 82: 1179-1194.

Jouvenceau A, Dutar P, Billard JM. Alteration of NMDA receptor-mediated synaptic responses in CA1 area of the aged rat hippocampus: contribution of GABAergic and cholinergic deficits. Hippocampus 1998; 8: 627-637.

Kadar T, Dachir S, Shukitt-Hale B, Levy A. Subregional hippocampus vulnerability in various animal models leading to cognitive dysfunction. J Neural Transpl 1998; 105: 987-1004.

Kerkut GA, Wheal HV. Electrophysiology of Isolated Mammalian CNS Preparations. London, England: Acadenic Press, 1981.

Kerr DS, Campbell LW, Applegate MD, Brodish A, Landfield PW. Chronic stress-induced acceleration of electrophysiological and morphometric biomarkers of hippocampal aging. J Neurophysiol 1991; 11: 1316-1324.

Kirino T. Delayed neuronal death in the gerbil hippocampus following ischemia. Brain Res 1982; 239: 57-69.

Kirov SA, Sorra KE, Harris KM. Slices have more synapses than perfusion-fixed hippocampus from both young and mature rats. J Neurophysiol 1999; 19: 2876-2886.

Landfield PW, Pitler TA, Applegate MD. The effects of high $\mathrm{Mg}^{2+}$ to $\mathrm{Ca}^{2+}$ ratios on frequency potentiation in hippocampal slices of young and aged rats. J Neurophysiol 1986; 56: 797-811.

LeJeune H, Cécyre D, Rowe W, Meaney MJ, Quirion $R$. Ionotropic glutamate receptor subtypes in the aged memory-impaired and unimpaired LongEvans rat. Neuroscience 1996; 74: 349-363.

Linseman MA, Corrigall WA. Neurophysiological evidence of movement of chronically implanted fine wire electrodes in recordings of field potentials in hippocampus. Physiol Behav 1981; 26: 729-733.

Lomo T. Patterns of activation in a mono synaptic cortical pathway: The perforant path input to the dentate area of the hippocampus formation. Exp Brain Res 1971; 12: 18-45.

Magnussen KR. Aging of glutamate receptors: Correlations between binding and spatial memory performance in mice. Mech Ageing Dev 1998; 104: 227-248.

Magnusson, Cotman, CW. Age-related changes in excitatory amino acid receptors in two mouse 
strains. Neurobiol Aging 1993; 14: 197-206.

Michaelis EK. Molecular biology of glutamate receptors in the central nervous system and their role in excitotoxicity, oxidative stress and aging. Prog Neurobiol 1998; 54: 369-415.

Miyoshi R, Kito S, Doudou N, Nomoto T. Effect of age on alpha-amino-3-hydroxy-5-methylisoxazole4-propionic acid (AMPA) binding sites in the rat brain studied by in vitro autoradiography. Neurochem Res 1991; 16: 849-854.

Nicolle MM, Bizon JL, Gallagher M. In vitro autoradiography of ionotropic glutamate receptors hippocampus and striatum of aged Long-Evans rats: relationship to spatial learning. Neuroscience 1996; 74: 741-756.

Norris CM, Halperin S, Foster TC. Alterations in the balance of protein kinase/protein phosphatase activities parallel reduced synaptic strength during aging. J Neurophysiol 1998; 80: 1567-1570.

Ordy JM, Thomas GJ, Volpe BT, Dunlap WP, Columbo PM. An animal model of human-type memory loss based on aging, lesion, forebrain ischemia, and drug studies with the rat. Neurobiol Aging 1988; 9: 667-683.

Ouanounou A, Zhang L, Charlton MP, Carlen PL. Differential modulation of synaptic transmission by calcium chelators in young and aged hippocampus CA1 neurons: Evidence for altered calcium homeostasis in aging. J Neurophysiol 1999; 19: 906-915.

Ouanounou A, Carlen PL, El-Beheury H. Enhanced isoflurane suppression of excitatory synaptic transmission in the aged rat hippocampus. Brain Res J Pharmacol 1998; 124: 1075-1082.

Pagliusi SR, Gerrard P, Abdallah M, Talabot D, Catsicas S. Age-related changes in expression of AMPA-selective glutamate receptor subunits: Is calcium permeability altered in hippocampal neurons? Neuroscience 1994; 61: 429-433.

Papatheodoropoulos C, Kostopoulos G. Age-related changes in excitability and recurrent inhibition in the rat CA1 hippocampus region. Eur J Neurosci 1996; 8: 510-520.

Paxinos G, Watson C. The Rat Brain in Stereotaxic Coordinates. Australia: Academic Press, 1986.

Potier B, Rascol O, Jazat F, Lamour Y, Dutar P. Alterations in the properties of hippocampus pyramidal neurons in the aged rat. Neuroscience 1992; 48: 793-806.

Potier B, Lamour Y, Dutar P. Age-related alterations in the properties of hippocampus pyramidal neurons among rat strains. Neurobiol Aging 1993; 14: 17-25.
Pulsinelli WA, Brierly JB, Plum F. Temporal profile of neuronal damage in a model of transient forebrain ischemia. Ann Neurol 1982; 11: 491-498.

Rao G, Stevenson GD, Barnes CA, McNaughton BL, Weaver KL. Age-related decrease in the Schaffer collateral evoked EPSP in chronically implanted F-344 rats. Soc Neurosci Abst 1996; 1870.

Reid KH, Edmonds HL Jr, Schurr A, Tseng MT, West CA. Pitfalls in the use of brain slices. Prog Neurobiol 1988; 31: 1-18.

Reynolds JN, Carlen PL. The effects of midazolam on hippocampus dentate gyrus granule neurons from young and old Fisher 344 rats. Can J Physiol Pharmacol 1989; 67: 359-362.

Roberts EL Jr, Rosenthal M, Sick TJ. Age-related modifications of potassium homeostasis and synaptic transmission during and after anoxia in rat hippocampal slices. Brain Res 1990; 514: 111-118.

Roberts EL Jr, Chih CP. Age-related alterations in energy metabolism contribute to the increased vulnerability of the aging brain to anoxic damage. Brain Res 1995; 678: 83-90.

Roberts EL Jr, Wisotzky D, Chih CP. Aging and the effects of MK-801 on anoxic damage in rat hippocampal slices. Brain Res 1998; 791: 321-324.

Rosenzweig ES, Rao G, McNaughton BL, Barnes CA. Role of temporal summation in age-related longterm potentiation-induction deficits. Hippocampus 1997; 7: 549-558.

Scheff SE, Anderson KJ, DeKosky ST. Strain comparison of synaptic density in hippocampus CA1 of aged rats. Neurobiol Aging 1985; 6: 29-34.

Schlander M, Hoyer S, Frotscher M. Glutamate decarboxylase-immunoreactive neurons in the aging rat hippocampus are more resistant to ischemia than CA1 pyramidal cells. Neurosci Lett 1988; 91: 241-246.

Schurr A, Reid KH, Tseng MT, Edmonds HL Jr, The stability of the hippocampal slice preparation: An electrophysiological and ultrastructural analysis. Brain Res 1984; 297: 357-362.

Schurr A, West CA, Rigor BM. Electrophysiology of energy metabolism and neuronal function in the hippocampal slice preparation. J Neurosci Meth 1989; 28: 7-13.

Shankar S, Teyler TJ, Robbins N. Aging differentially alters forms of long-term potentiation in rat hippocampus area CA1. J Neurophysiol 1998, 79: 334-341.

Shen J, Barnes CA. Age-related decrease in cholinergic synaptic transmission in three hippocampal subfields. Neurobiol Aging 1996; 17: 439-451. 
Sullivan P, Feng Z, Price DA, Hamrick J, Callihan CT, McAllister, et al., Unbiased estimation of possible age-related changes in total number of synapses in the hippocampal CA1 region of the rat. Soc Neuroscience Abstr 1997; 1459.

Syková E, Mazel T, Simonová Z. Diffusion constraints and neuron-glia interaction during aging. Exp Gerontol 1998; 33: 837-851.

Tanaka K, Fukuuchi Y, Nozaki H, Nagata E, Kondo $T$, Dembo T. Acute ischemic vulnerability of PKA in the dendritic subfields of the hippoampus CA1. NeuroReport 1997; 8: 2423-2428.

Teyler TJ. Brain slice preparation: Hippocampus.
Brain Res Bull 1980; 5: 391-403.

Thibault O, Landfield PW. Increase in single L-type calcium channels in hippocampus neurons during aging. Science 1996; 272: 1017-1020.

Wardas J, Pietraszek M, Schulze G, Ossowska K, Wolfarth S. Age-related changes in glutamate receptors: an autoradiographic analysis. Pol J Pharmacol 1997; 49: 6401-6410.

$\mathrm{Xu}$ ZC, Pulsinelli WA. Electrophysiological changes of CA1 pyramidal neurons following transient forebrain ischemia: An in vivo intracellular recording and staining study. J Neurophysiol 1996; 76: 1689-1697. 

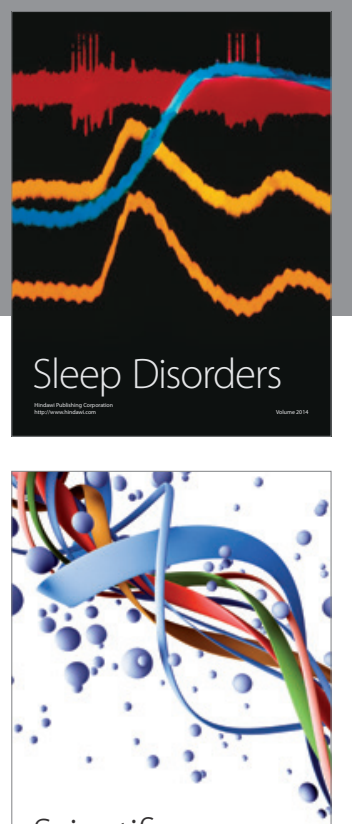

Scientifica
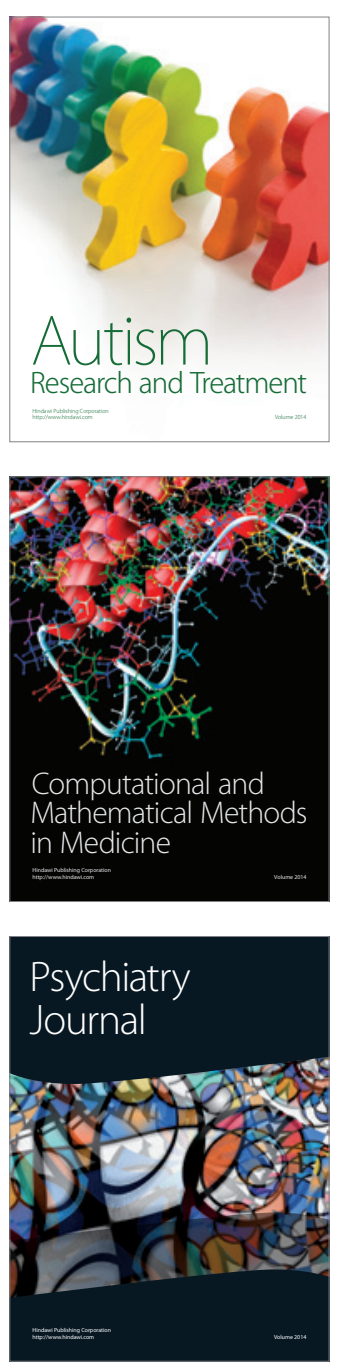
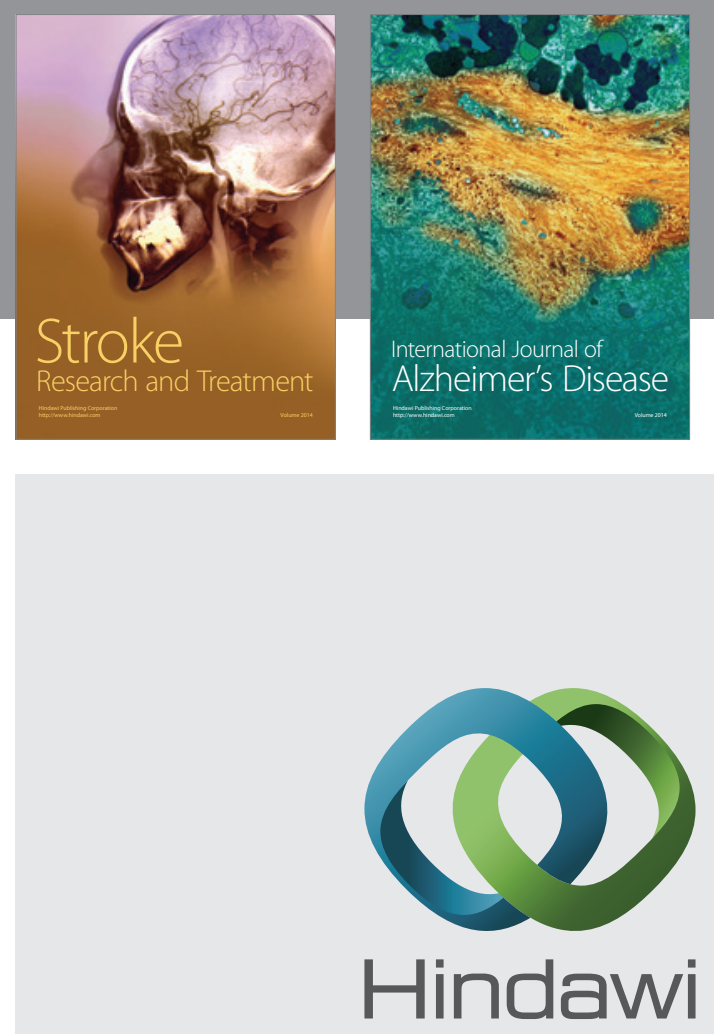

Submit your manuscripts at

http://www.hindawi.com
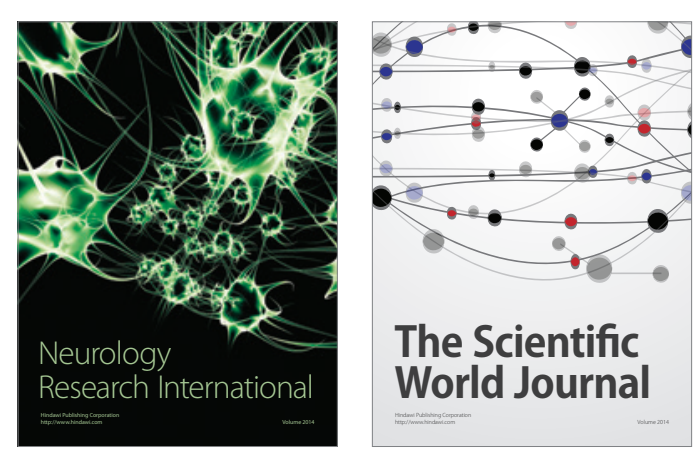

The Scientific World Journal

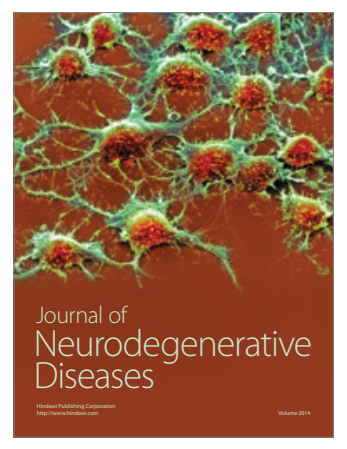

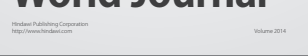

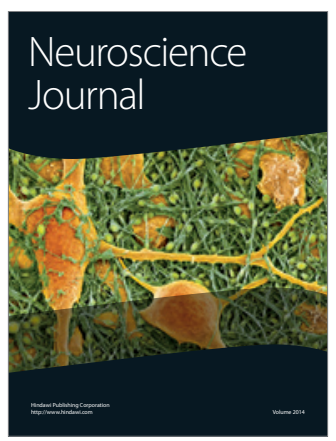

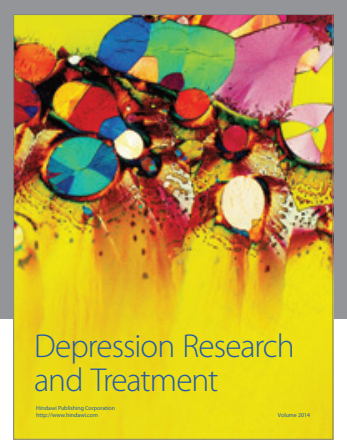
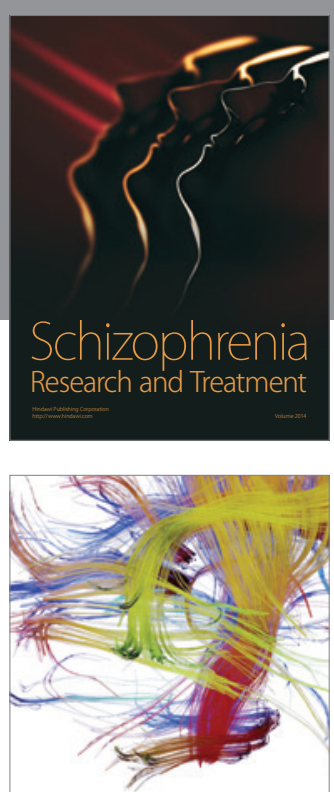

Brain Science

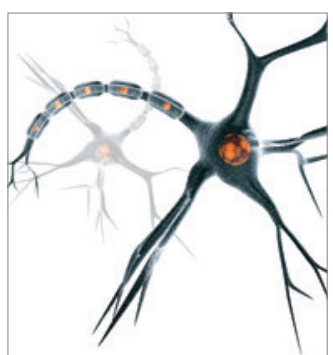

Neural Plasticity
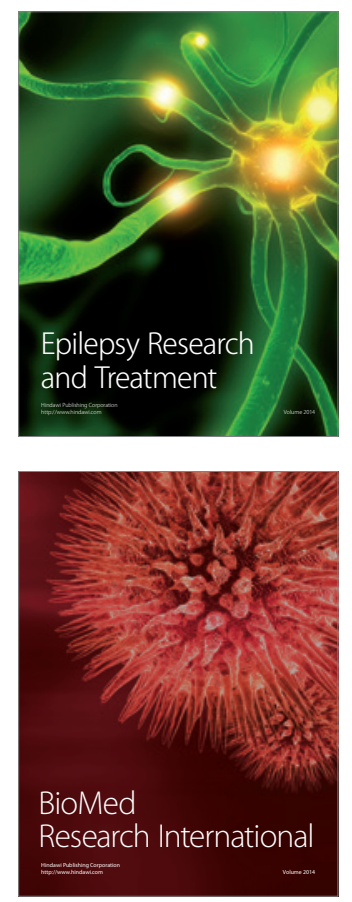

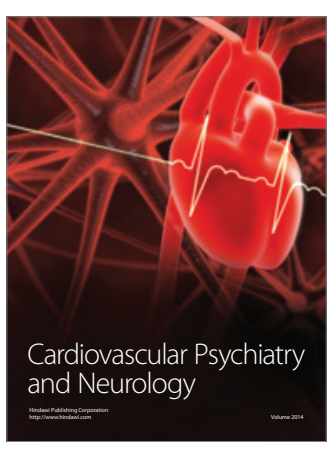

Parkinson's

Disease
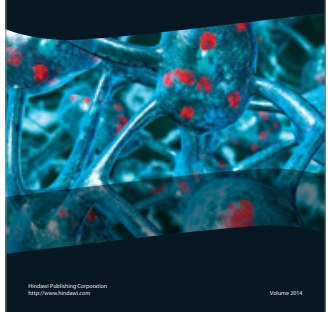